\begin{tabular}{|c|c|}
\hline $4 E$ European Association for the & $\begin{array}{c}\text { International Conference on Renewable Energies and Power Quality } \\
\text { (ICREPQ' 12) }\end{array}$ \\
$\begin{array}{c}\text { Development of Renewable Energies, Environment } \\
\text { and Power Quality (EA4EPQ) }\end{array}$ & Santiago de Compostela (Spain), 28th to 30th March, 2012 \\
\hline
\end{tabular}

\title{
Analysis of a Single-Phase Line-Interactive UPS System
}

\author{
R. A. Modesto ${ }^{1}$, S. A. O. Silva ${ }^{1}$, R. Barriviera ${ }^{2}$ and M. Kaster ${ }^{1}$ \\ Department of Electrical Engineering \\ ${ }^{1}$ Federal Technological University of Paraná - UTFPR \\ Av. Alberto Carazzai, 1640, CEP-86300-000 Cornélio Procópio-PR (Brazil) \\ Phone: +55 (43) 3520-4000, Fax: +55 (43) 3520-4010, \\ e-mail: rodrigomodesto@utfpr.edu.br, augus@utfpr.edu.br, mkaster@utfpr.edu.br \\ Department of Electrotechnic \\ ${ }^{2}$ Federal Institute of Paraná - IFPR \\ PR466 - Gleba Pindaúva - Secção C - Parte 2 - CEP 86870-000 Ivaiporã-PR (Brazil) \\ Phone: +55 (43) 3472-0763, e-mail: rodrigo.barriviera@ifpr.edu.br
}

\begin{abstract}
This paper presents an analysis of a single-phase line interactive uninterruptible power supply (UPS) system, allowing output voltage conditioning, such as voltage harmonic suppression and sag/swell compensation. Additionally, the UPS input current is also compensated, allowing current harmonic suppression and reactive power compensation. In other words, the UPS system acts as a true unified power quality conditioner (UPQC), when working in standby operation mode. The power rate handled by both series and parallel PWM converters depend on the operation conditions of the UPS system, such as the amplitude of the fundamental input voltage, the total harmonic distortion of the load current, fundamental power factor of the load, battery charging, among others. In standby mode, the amplitude of the UPS output voltage will be allowed to vary in order to follow the amplitude of the input voltage within a limited range defined by design requirements. This strategy will allow an effective optimization of the efficiency of the UPS system. Mathematical analyses of the single-phase line interactive UPS system are presented in order to obtain the state space models of the two PWM converters. Validation results are presented in order to evaluate the performance of the line interactive UPS system.
\end{abstract}

\section{Key words}

Harmonic suppression, Reactive power compensation, SRF-based controller, UPS system.

\section{Introduction}

The growing use of nonlinear loads by industrial, commercial and residential consumers have contributed to increase the utility voltage distortions, which is verified by means of the high content of harmonic currents drained from the power supply systems.

Parallel active power filters (APFs) have contributed to mitigate the effects on the power system caused by the circulation of harmonic currents generated by nonlinear loads and power [1-3]. Series APFs have been used to compensate utility voltage disturbances, such as sags, swells, harmonic voltages, etc. [3-4]. On the other hand, series and parallel active filtering capability can be simultaneously performed by means of unified power quality conditioners (UPQCs) [5-7].

Specifically, uninterruptible power supply (UPS) systems have been employed in order to provide clean and uninterruptible power to critical loads such as, industrial controls, computers, medical equipments, and others, against power supply disturbances, such as sags, swells, outages, etc.

Thus, under normal and abnormal incoming power conditions, UPS systems must be able to make the currents drained from the utility grid, sinusoidal with low harmonic contents. Simultaneously, it must provide to the load, balanced, regulated, and sinusoidal voltages with low total harmonic contents.

Similar to UPQCs the line-interactive UPS system discussed in this paper acts as series and parallel APFs, when is operating in standby mode [8-12]. The series PWM converter works as a sinusoidal current source while the parallel PWM converter works as a sinusoidal voltage source. The PWM converters are controlled to operate in phase with the input voltage.

Since, in standby mode, the UPS system operates as a UPQC, its efficiency is linked with both utility voltage and load conditions. Thereby, the power rates handled by the series and parallel PWM converters depend not only on the amplitude and harmonic contents of the input voltage, but also on the load fundamental power factor and on the harmonic contents of the load currents. Besides, the battery charging has also influence on the power rate of the PWM converters.

The aim of this paper is to present plotted curves that allow determining the power rate handled by the PWM converters considering different conditions of the utility grid and loads. In addition, taking into account the power flow through the UPS system when it is operating as a UPQC, a strategy that allows the increasing of the PWM converters efficiency is also presented. 


\section{UPS Topology}

The topology of the single-phase line-interactive UPS system is shown in Fig. 1, which uses two single-phase full-bridge PWM converters coupled to a common DClink to perform the series and parallel APF functions. When the incoming power is normal, the series PWM converter is controlled to behave as a sinusoidal current source, while the parallel PWM converter is controlled to behave as a sinusoidal voltage source.

The DC-link can be performed through a battery bank. A static switch ' $s w$ ' protects the critical loads, providing a fast disconnection between the UPS and the power supply when an occasional interruption of the incoming power occurs. In this case, the static switch ' $s w$ ' is opened and the series converter is disabled. Meanwhile, the parallel converter remains operating normally without any voltage transient transferred to the load.

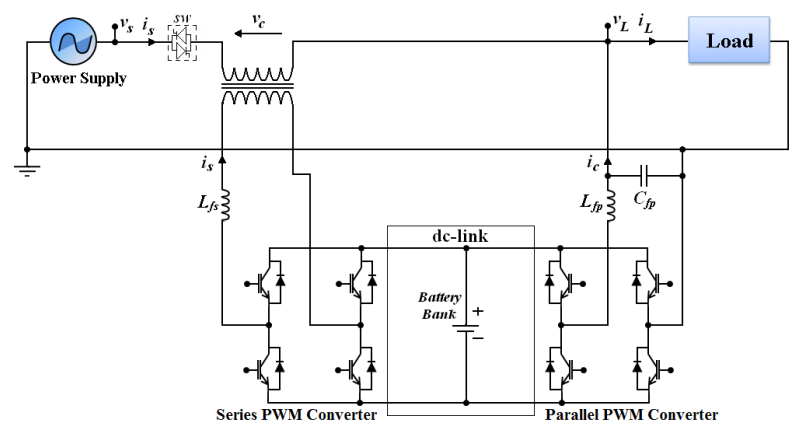

Fig. 1. Single-Phase Line-interactive UPS System.

\section{Voltage and Current References of the Series and Parallel Converters}

Since the series PWM converter is controlled to make the source currents $\left(i_{s}\right)$ sinusoidal and in phase with the power supply voltage $\left(v_{s}\right)$, it must behave as a current source with a high enough impedance to isolate the line from the load harmonic currents. Similarly, the parallel PWM converter is controlled to act as a sinusoidal voltage source, such that regulated and sinusoidal output voltage $\left(v_{L}\right)$ is provided to the load. Any voltage disturbances such as sags, swells, harmonics and transients are handled by the series PWM converter through the series transformer. In addition, the parallel converter must behave as a voltage source with a low enough impedance to absorb the harmonic currents of the load. As with the source current, the output voltage is also controlled to be in phase with the power supply voltage.

\section{A. Current SRF-Based Controller}

The current synchronous reference frame (SRF)-based controller applied to single-phase loads is shown in Fig. 2 (a). Measuring the load current $\left(i_{L}\right)$ provides the twophase stationary reference frame $\alpha \beta$ quantities $\left(i_{\alpha}, i_{\beta}\right)$. The acquired load current is treated as the ' $\alpha$ ' coordinate of the fictitious two-phase stationary reference frame $(\alpha \beta)$. Subsequently, $i_{\alpha}$ has a $\pi / 2$ radian phase delay, producing the fictitious $\beta$ coordinate $\left(i_{\beta}\right)$. Therefore, a new two-phase system, represented by (1), can be studied in the $\alpha \beta$-axes. The $d$ value $\left(i_{d}\right)$ of the SRF-based controller is obtained by (2), where the phase-angle is obtained from a PLL system, which will be identical to the utility phase-angle $\theta$. The $d$-axis quantity $i_{d_{d c}}$ is found from $i_{d}$ by using a Low-Pass Filter (LPF).

The total direct current component $i d_{T d c}^{*}$, given by (3), is reached by adding $i_{d_{d c}}$ to the component obtained from the DC-link controller $\left(i_{d c}\right)$. It represents the positive sequence component of the load current added to the current necessary to the battery charging. In other words, $i d_{T d c}^{*}$ represents the active current drained from the utility grid.

$$
\begin{gathered}
{\left[\begin{array}{c}
i_{\alpha} \\
i_{\beta}
\end{array}\right]=\left[\begin{array}{c}
i_{L}(\omega t) \\
i_{L}(\omega t-\pi / 2)
\end{array}\right]} \\
i_{d}=i_{\alpha} \cos \theta+i_{\beta} \sin \theta \\
i d_{T d c}^{*}=i_{d c}+i_{d c}
\end{gathered}
$$

The quantity $i_{d c}$ (Fig. 2a) is the output signal of the DCbus controller (PI controller), which represents the compensation of the losses related to the inductances and switching devices. In other words, the PI output signal $i_{d c}$ represents the total active power demanded by the conditioners to regulate the DC-link voltage.

\section{B. Voltage SRF-Based Controller}

The voltage SRF-based controller applied to single-phase loads is shown in Fig. 2 (b).

The $d$ quantity $\left(v_{s d}\right)$ of the SRF-based controller is obtained by (4), where $v_{s \alpha}$ is the measured input voltage. Subsequently, $v_{s \alpha}$ has a $\pi / 2$ radian phase delay, producing the fictitious $\beta$ coordinate $\left(v_{s \beta}\right)$.

$$
v_{s d}=v_{s \alpha} \cos \theta+v_{s \beta} \sin \theta
$$

The filtered $d$-axis component $v_{L d}$ (Fig. 2b) is obtained from $v_{s d}$ by using a LPF. Thus, $v_{L d}$ is proportional to the amplitude of the UPS output voltage reference. Normally this quantity is set to be constant and it is obtained directly from a PLL system.

However, due to the fact that the difference between the input and output voltages will interfere in the power flow through the UPS, and consequently increasing the power rate of the PWM converters [9], it is convenient to change the amplitude of the output voltage in order to follow the amplitude of the input voltage within a limited range. This procedure will contribute to increase the total efficiency of the UPS system. Obviously, the voltage variation range must be limited in order to satisfy the load voltage requirements. Figure 2 (b) shows the upper and lower limits used to define the range of the UPS output voltage. 


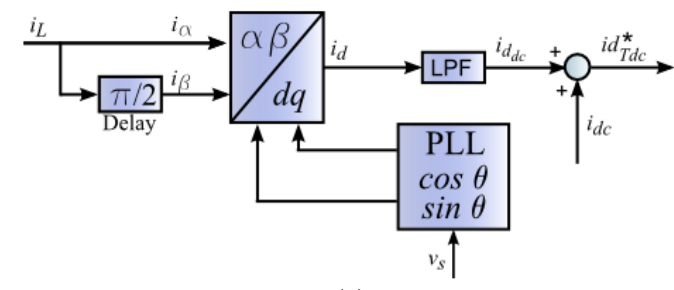

(a)

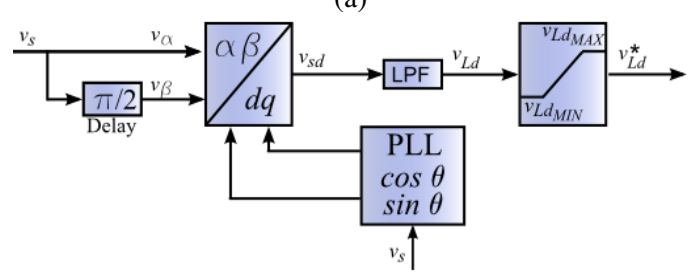

(b)

Fig. 2. Block diagrams: (a) Current SRF-based controller; (b) Voltage SRF-based controller.

\section{State Feedback Current and Voltage Controllers}

In this section the state feedback controllers used in the single-phase UPS system are presented, which are implemented in $d q$-axes.

\section{A. State Feedback Current Controller (Series APF)}

The control of the series PWM converter is implemented based on SRF controller. Thereby, the mathematical modeling is presented in order to obtain the state space system and the transfer functions in the $d q$ frame. To perform the modeling, the coupling inductance $L_{f s}$ and its resistance $R_{f s}$, and the series transformer voltage $v_{c}$ are shown in Fig. 1. Thus, from Fig. 3, state equation of the system can be expressed by (5).

$$
\frac{d i_{s}}{d t}=-\frac{R_{L f s}}{L_{f s}} i_{s}-\frac{1}{L_{f s}} v_{c}+\frac{1}{L_{f s}} u_{p w m_{s}}
$$

The state-space system is defined as:

$$
\dot{x}(t)=A x(t)+B u(t)+F w(t)
$$

where $\dot{x}(t)=\frac{d i_{s}}{d t} ; x(t)=i_{s} ; u(t)=u_{p w m_{s}} ; w(t)=v_{c}$.

The state equation in the synchronous frame $d q$, is given by (7).

$$
\left[\begin{array}{l}
\dot{i}_{d_{s}} \\
\dot{i}_{q_{s}}
\end{array}\right]=A_{d q_{s}}\left[\begin{array}{l}
i_{d_{s}} \\
i_{q_{s}}
\end{array}\right]+B_{d q_{s}}\left[\begin{array}{l}
u_{d p w m_{s}} \\
u_{q p w m_{s}}
\end{array}\right]+F_{d q_{s}}\left[\begin{array}{l}
v_{d_{c}} \\
v_{q_{c}}
\end{array}\right]
$$

where $A_{d q_{s}}=\left[\begin{array}{cc}-\frac{R_{L f s}}{L_{f s}} & \omega \\ -\omega & -\frac{R_{L f s}}{L_{f s}}\end{array}\right] ; B_{d q_{s}}=\left[\begin{array}{cc}\frac{1}{L_{f s}} & 0 \\ 0 & \frac{1}{L_{f s}}\end{array}\right]$

$$
F_{d q_{s}}=\left[\begin{array}{cc}
\frac{1}{L_{f s}} & 0 \\
0 & \frac{1}{L_{f s}}
\end{array}\right] \text {. }
$$

The block diagram of the physical system in $d q$-axes is shown in Fig. 3, where $D_{d}$, and $D_{q}$ are the duty cycles in the synchronous reference frame, which are obtained from the PWM, and $V_{d c}$ is the DC-bus voltage.

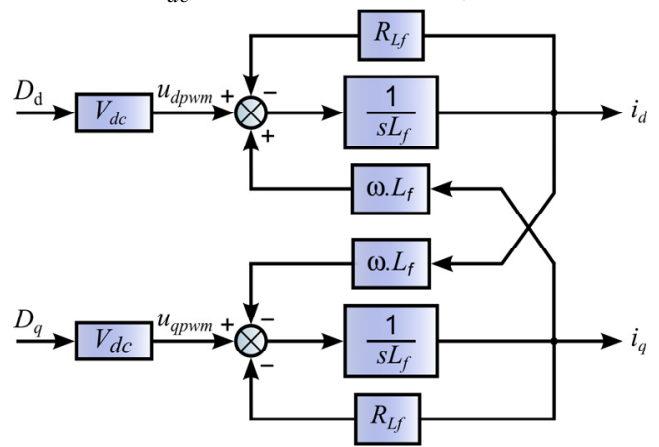

Fig. 3. Physical system model of the UPS in $d q$ coordinates (Series APF).

The cross-coupling between the direct and quadrature axes can be eliminated using the decoupled model shown in Fig. 4, where the shaded block is the decoupling term.

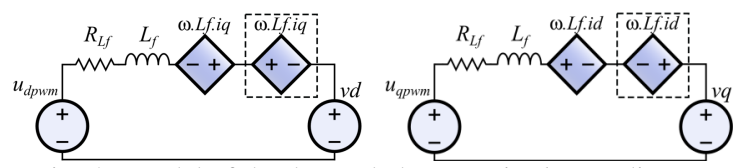

Fig. 4. Model of the decoupled system in $d q$ coordinates.

Thus, in the synchronous $d q$-frame, neglecting the crosscoupling, the transfer functions of the system $G_{s(d, q)}$ is given by (8).

$$
G_{s(d, q)}(s)=\frac{1}{\left(s L_{f s}+R_{L f s}\right)}
$$

The block diagram of the current controller is shown in Fig. 5 (a), where PI controllers are used. Thereby, the closed loop transfer functions $I_{d, q}(s) / I_{d, q}^{*}(s)$ is obtained, as follows:

$$
\frac{I_{d, q}(s)}{I_{d, q}^{*}(s)}=\frac{K p_{i(d, q)} s+K i_{i(d, q)}}{L_{f s} s^{2}+\left(R_{L f s}+K p_{i(d, q)}\right) s+K i_{i(d, q)}}
$$

The details of the Current Reference Generation and Current Control block, represented in Fig. 5 (a), are shown in Fig. 5 (b).

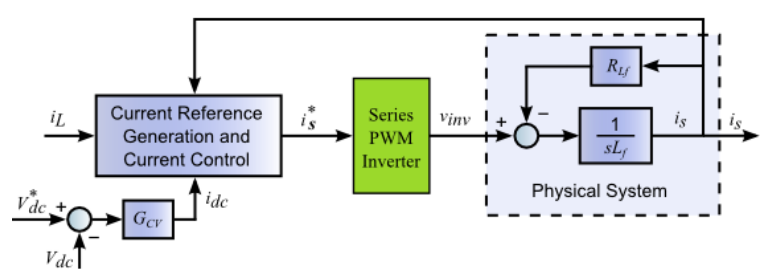

(a)

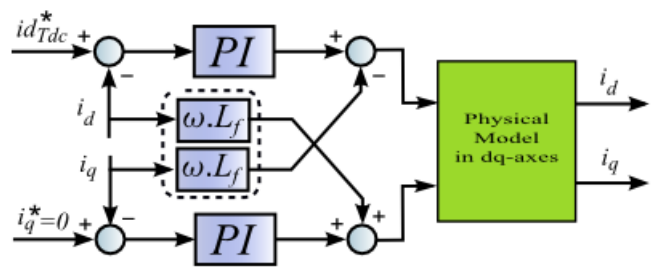

(b)

Fig. 5. Block Diagrams: (a) Current controller; (b) Current Reference Generation and Current Control. 


\section{B. State Feedback Current Controller (Parallel APF)}

The control of the parallel PWM converter is also implemented based on SRF controller. Thereby, the mathematical modeling is presented in order to obtain the state space system and the transfer functions in the $d q$ frame. To perform the modeling, the coupling inductance $L_{f p}$ and its resistance $R_{f p}$, and the filter capacitor $C_{f p}$ are shown in Fig. 1. Thus, from Fig. 1, state equations of the system can be expressed by (10) and (11).

$$
\begin{gathered}
\frac{d i_{L f_{p}}}{d t}=-\frac{R_{L f p}}{L_{f p}} i_{L f_{p}}-\frac{1}{L_{f p}} v_{C_{f p}}+\frac{1}{L_{f p}} u_{p w m} \\
\frac{d v_{C_{f p}}}{d t}=\frac{1}{C_{f p}} i_{L_{f p}}-\frac{1}{C_{f p}} i_{o}
\end{gathered}
$$

The state equations in the synchronous frame $d q$, is given by (12).

$$
\begin{aligned}
& {\left[\begin{array}{l}
\dot{i}_{d p} \\
\dot{i}_{q_{p}} \\
\dot{v}_{d p} \\
\dot{v}_{q_{p}}
\end{array}\right]=A_{d q_{p}}\left[\begin{array}{l}
i_{d p} \\
i_{q_{p}} \\
v_{d p} \\
v_{q_{p}}
\end{array}\right]+B_{d q_{p}}\left[\begin{array}{l}
u_{d p w m_{p}} \\
u_{q p w m_{p}}
\end{array}\right]+F_{d q_{p}}\left[\begin{array}{l}
i_{o d} \\
i_{o q}
\end{array}\right]} \\
& \text { where } A_{d q_{p}}=\left[\begin{array}{cccc}
-\frac{R_{L f p}}{L_{f p}} & \omega & -\frac{R_{L f p}}{L_{f p}} & 0 \\
-\omega & -\frac{R_{L f p}}{L_{f p}} & 0 & -\frac{R_{L f p}}{L_{f p}} \\
\frac{1}{L_{f p}} & 0 & 0 & \omega \\
0 & \frac{1}{C_{f p}} & -\omega & 0
\end{array}\right] \text {; } \\
& B_{d q_{p}}=\left[\begin{array}{cc}
\frac{1}{L_{f p}} & 0 \\
0 & \frac{1}{L_{f p}} \\
0 & 0 \\
0 & 0
\end{array}\right] ; F_{d q_{p}}=\left[\begin{array}{cc}
0 & 0 \\
0 & 0 \\
-\frac{1}{C_{f p}} & 0 \\
0 & -\frac{1}{C_{f p}}
\end{array}\right] \text {. }
\end{aligned}
$$

The block diagram of the physical system in $d q$-axes is shown in Fig. 6, where $D_{d}$, and $D_{q}$ are the duty cycles in the synchronous reference frame, which are obtained from the PWM, and $V_{d c}$ is the DC-bus voltage.

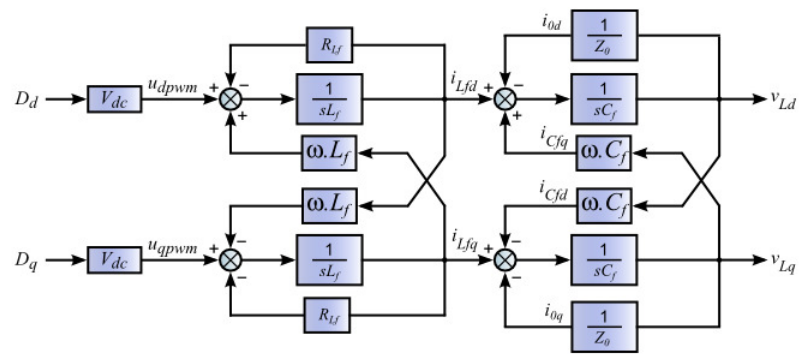

Fig. 6. Physical system model of the UPS in $d q$ coordinates (Parallel APF).

The cross-coupling between the direct and quadrature axes can be eliminated using the decoupled model shown in Fig. 7, where the shaded block is the decoupling term.

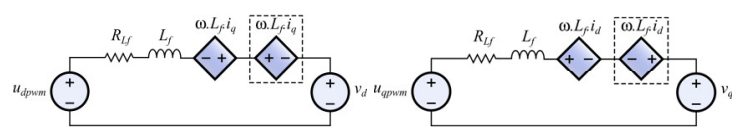

Fig. 7. Model of the decoupled system in $d q$ coordinates.

Thus, in the synchronous $d q$-frame, neglecting the crosscoupling, the transfer functions of the system $G_{p(d, q)}$ is given by (13).

$$
G_{p(d, q)}(s)=\frac{1}{\left(s^{2} L_{f p} C_{f p}+s R_{L f p} C_{f p}+1\right)}
$$

The block diagram of the current controller is shown in Fig. 8 (a), where the PI controller is used. Thereby, the closed loop transfer functions $V_{d, q}(s) / V_{d, q}^{*}(s)$ is obtained, as follows:

$$
\frac{V_{d, q}(s)}{V_{d, q}^{*}(s)}=\frac{X_{1} s^{2}+X_{2} s+X_{3}}{Y_{1} s^{3}+Y_{2} s^{2}+Y_{3} s+Y_{4}}
$$

where

$$
\left.\begin{array}{cc}
X_{1}=\hat{C}_{f p} \cdot K_{p i_{(d, q)}} & Y_{1}=L_{f p} \cdot C_{f p} \\
X_{2}=K_{p v_{(d, q)}} \cdot K_{p i(d, q)} & Y_{2}=C_{f p} \cdot\left(K_{p i_{(d, q)}}+R_{L f p}\right) \\
X_{3}=Y_{4}=K_{i v_{(d, q)}} \cdot K_{p i_{(d, q)}} & Y_{3}=K_{p v_{(d, q)}} \cdot K_{p i_{(d, q)}}+1
\end{array}\right\}
$$

The details of the Voltage Reference Generation and Voltage Control block, represented in Fig. 8 (a), are shown in Fig. 8 (b).

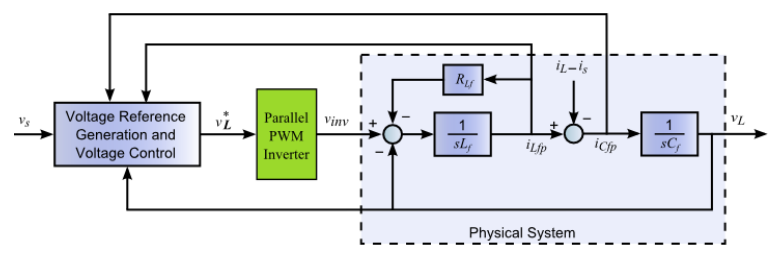

(a)

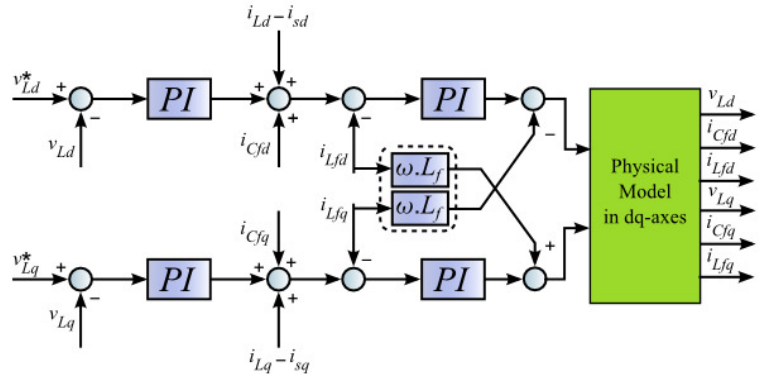

(b)

Fig. 8. Block Diagrams: (a) Voltage controller; (b) Voltage Reference Generation and Voltage Control.

\section{Power Flow Through the UPS System}

The apparent powers handled by the parallel and series converters, $S_{p}$ and $S_{S}$, respectively, depend on the ratio between the output and input rms voltages $\left(V_{L} / V_{s}\right)$, the fundamental power factor $\left(\cos \varphi_{1}\right)$, the THD of the load current $i_{L} \quad\left(T H D_{i_{L}}\right)$ and the battery charging factor $k_{b}=P_{b} / P_{L}$, where $P_{b}$ is the active power used to charge the UPS batteries and $P_{L}$ is the active power demanded 
by the load. In steady state, assuming that the input current and the output voltage are sinusoidal, the normalized powers handled by the parallel converter $\left|S_{p} / S_{L}\right|$ and by the series converter $\left|S_{s} / S_{L}\right|$ are given by (16) and (17), respectively, where $S_{L}$ is the apparent power of the load [9]. Figure 9 allows verifying the influence of ratio $V_{s} / V_{L}$ and the factor $k_{b}$ over the normalized power $\left|S_{p} / S_{L}\right|$ and $\left|S_{s} / S_{L}\right|$ considering a typical load with $\cos \varphi_{1}=1$ and $T H D_{i L} \%=48 \%$, and $k_{b}$ varying from 0 to 0.5 . As can be noted if the ratio $V_{s} / V_{L}$ is equal to 1 the efficiency of the UPS system is improved. In these curves the harmonic distortion of the input voltage $v_{s}$ was not took into account.

$$
\begin{gathered}
\left|\frac{S_{s}}{S_{L}}\right|=\frac{\cos \phi_{1} \sqrt{\left[\left(1+k_{b}\right)\left(1-V_{L} / V_{s}\right)\right]^{2}}}{\sqrt{1+T D H_{i_{L}}^{2}}} \\
\left|\frac{S_{p}}{S_{L}}\right|=\sqrt{\frac{\cos ^{2} \phi_{1} \frac{V_{f}}{V_{s}}\left(1+k_{b}\right)\left(\frac{V_{L}}{V_{s}}\left(1+k_{b}\right)-2\right)}{1+T D H_{i_{L}}^{2}}+1}
\end{gathered}
$$

Analysis of (16) and (17) revels that the direction of the active power flowing through the UPS depends on the difference between the utility and output voltages and the battery charging factor $k_{b}$. Depending on the $k_{b}$ value and the input voltage deviation from the desired output voltage, the battery charging can be performed either from the series or parallel PWM converters or from both.

Considering the charging factor $\left(k_{b}\right)$ is equal to zero, Fig. 10 (a) and (b) show the active instantaneous powers flowing through the UPS considering two situations, such as $V_{s}>V_{L}$ and $V_{s}<V_{L}$, where the power supply system, series converter power, parallel converter power and load power are represented by $p_{s}, p_{c s}, p_{c p}$ and $p_{L}$, respectively, with $p_{o}=p_{L}-p_{c p}=p_{s}-p_{c s}$.

Therefore, to make up the balance of the active power on the DC-bus the amplitude of the series reference current must be controlled, which is performed by means of an additional DC-bus controller, as shown in Fig. 5 (a).

\section{Simulation Results}

To verify the behavior of the UPS topology, it was simulated with the computational tool PSIM Version $9.0^{\circledR}$, in which the single-phase converters operate at $20 \mathrm{kHz}$ switching frequency. The simulations were performed considering a single-phase system feeding nonlinear load. The UPS operating in standby and backup modes is shown in Figs. 11 and 12. For standby and backup operation modes, the input, series and output UPS voltages are shown in Fig. 11, while the input, parallel and output currents are shown in Fig. 12. The UPS working as UPQC, and performing the compensation of harmonic voltages, and sag/swell disturbances, are shown in Figs. 13 and 14. In Figs. 13 and 14 (a), from 0s up to 104.16ms the power supply system is operating at nominal voltage. After that, from $104.16 \mathrm{~ms}$ up to $187.5 \mathrm{~ms}$ the system operates with sag disturbance.

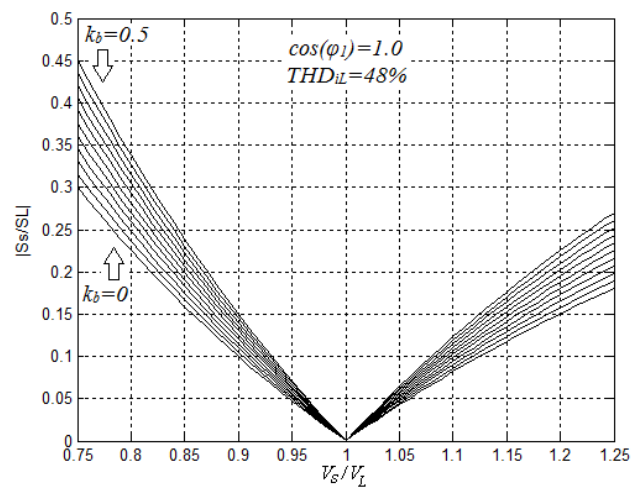

(a)

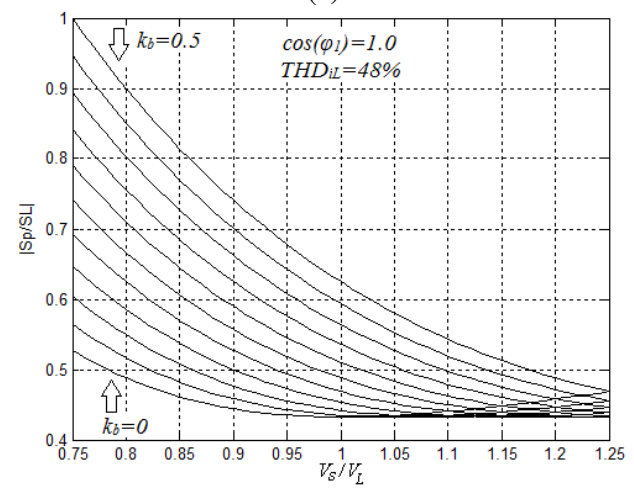

(b)

Fig. 9. Normalized curves: (a) $S_{s} / S_{L}$; (b) $S_{p} / S_{L}$.

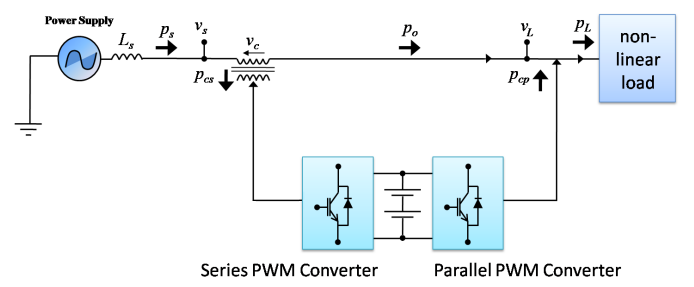

(a)

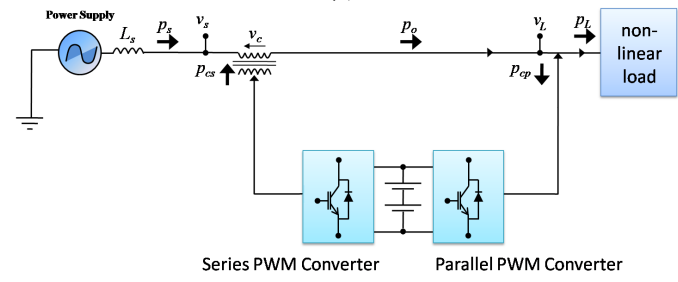

(b)

Fig. 10. Power flow through of the UPS system:

$$
\text { (a) } V_{s}>V_{L} \text {; (b) } V_{s}<V_{L} \text {. }
$$

The swell disturbance occurs between $295.83 \mathrm{~ms}$ and 404.16ms. Figs. 13 and 14 (b) show the controlled sinusoidal and harmonic free output voltage, while Figs. 13 and 14 (c) show the rms input and output voltages.

While in Fig 13 the output voltage is fixed at its nominal value (Strategy 1), in Fig. 14 is allowed a variation of $\pm 5 \%$ of the load voltage in order to increase the efficiency of the UPS (Strategy 2).

Fig. 15 shows the instantaneous active power that flows through the series converter for the two strategies adopted. As can be noted the power that flows through the series converter in Fig. 15 (a) is lower than that shown in Fig. 15 (b) during the voltage disturbances. Thus, the Strategy 2 can contribute to increase the efficiency of the UPS system during normal and abnormal utility conditions. 

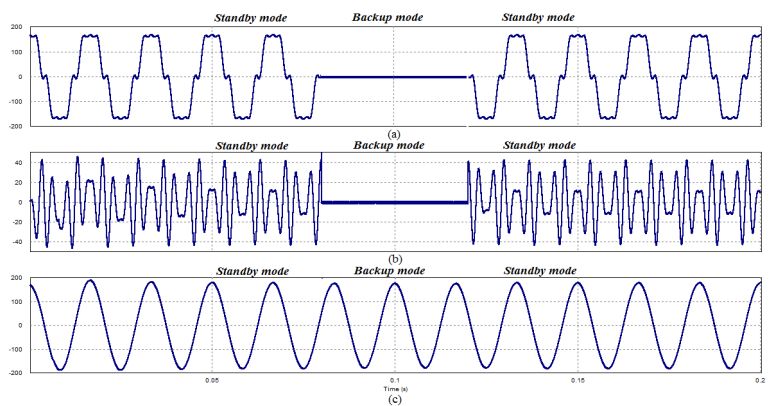

Fig. 11. Standby-Backup UPS Voltages: (a) Input voltage $\left(v_{s}\right)$; (b) Series Voltage $\left(v_{c}\right)$; (c) Output voltage $\left(v_{L}\right)$.

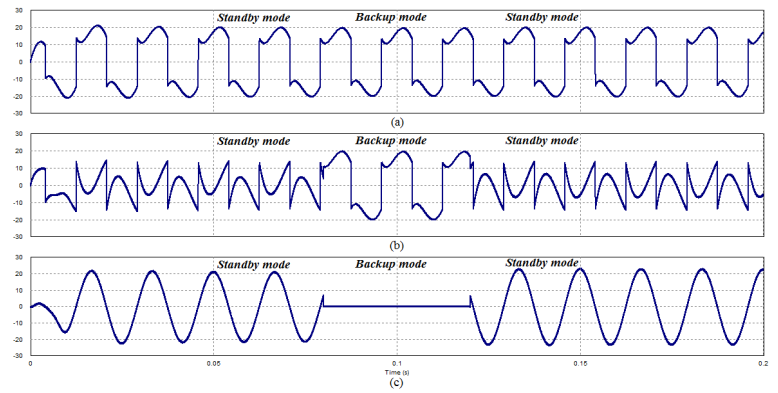

Fig. 12. Standby-Backup UPS Currents: (a) Load Current $\left(i_{L}\right)$; (b) Shunt current $\left(i_{c}\right)$; (c) Input current $\left(i_{s}\right)$

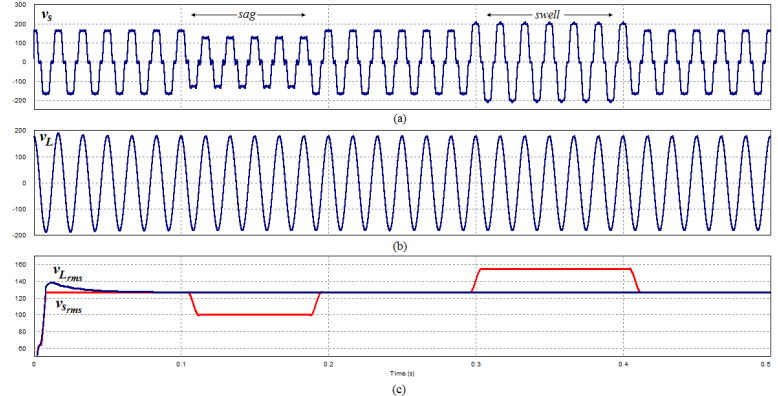

Fig. 13. UPS Voltages: (a) Input voltage ( $\left.v_{S}\right)$; (b) Output voltage $\left(v_{L}\right)$; (c) rms output and input voltages $\left(v_{\text {Lrms }}, v_{\text {srms }}\right)$.

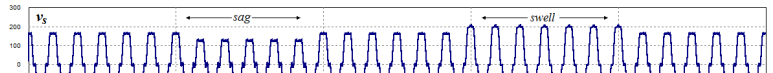

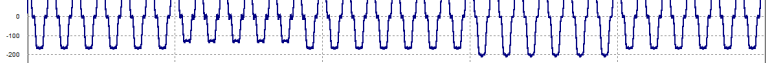

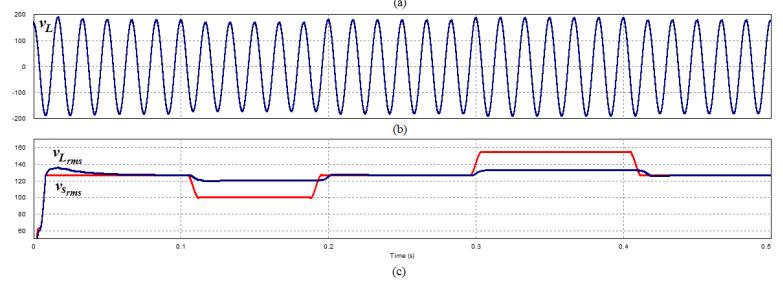

Fig. 14. UPS Voltages: (a) Input voltage $\left(v_{s}\right)$; (b) Output voltage $\left(v_{L}\right)$; (c) rms output and input voltages $\left(v_{\text {Lrms }}, v_{\text {srms }}\right)$.

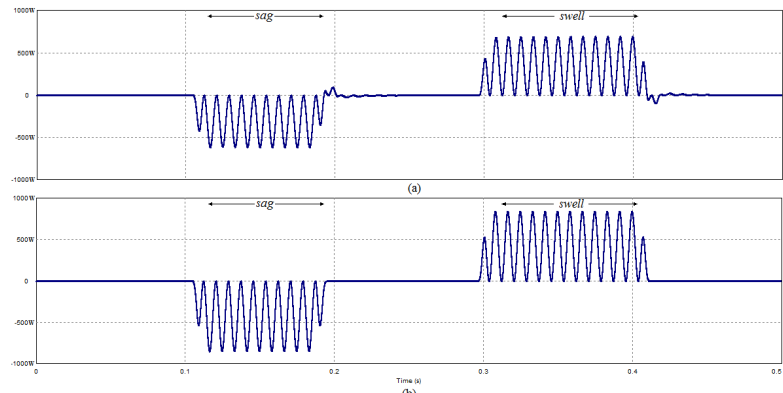

Fig. 15 Instantaneous active power through the series converter.

\section{Conclusion}

This paper presented an analysis of a single-phase line interactive uninterruptible power supply (UPS) system, allowing the output voltage conditioning, such as voltage harmonic suppression and sag/swell compensation. Additionally, the UPS input current was also compensated, allowing current harmonic suppression and reactive power compensation.

Curves that allow to identify the power rate handled by both series and parallel PWM converter were presented, as well as a strategy employed to increase the efficiency of the UPS was implemented.

Validation results were presented in order to evaluate the performance of the line interactive UPS system.

\section{Acknowledgement}

The authors gratefully acknowledge the financial support received from CNPq, process $n^{\circ} 471825 / 2009-3$, and from Araucária Foundation.

\section{References}

[1] M.I.M. Monteiro, E.R. Cadaval, and F.B. González, "Comparison of Control Strategies for Shunt Active Power Filters in Three-Phase Four-Wire System," IEEE Trans. on Power Electronics, vol. 22, no. 1, pp. 229-236, Jan. 2007.

[2] S.A.O. Silva, A. Feracin, S.G. Cervantes, A. Goedtel, and C.F. Nascimento, "Synchronous Reference Frame Based Controllers Applied to Shunt Active Power Filters in ThreePhase Four-Wire Systems," in Proc. of IEEE ICIT, 2010.

[3] P. Salmarón, S. P. Litrán, S. R. Herrera, and J. R. Vázquez "A Pratical Comparative Evaluation of Different Active Harmonic Filter Topologies" in Proc. of ICREPQ, 2011.

[4] J.W. Dixon, G. Venegas, and L.A. Morán, "A Series Active Filter Based on Sinusoidal Current-Controlled VoltageSource Inverter," IEEE Trans. on Industrial Electronics, vol. 44, no. 5, pp. 612-619, October 1997.

[5] H. Fujita and H. Akagi, "The Unified Power Quality Conditioner: The Integration of Series and Shunt Active Filters," IEEE Trans. on Power Electronics, vol. 13, no. 2, pp. 315-322, March 1998.

[6] M. Aredes, K. Heumann, and E.H. Watanabe, "A Universal Active Power Line Conditioner," IEEE Trans. on Power Delivery, vol. 13, no. 2, pp. 545-551, April 1998.

[7] M. Ucar, S. Ozdemir, and E. Ozdemir"A Control Strategy for Combined Series-Parallel Active Filter System under Non-Periodic Conditions" in Proc. of ICREPQ, 2009.

[8] F. Kamran and T. Habetler, "A Novel On-Line UPS with Universal Filtering Capabilities," IEEE Trans. on Industry Electronics, vol. 13, no. 2, pp. 366-371, March 1998.

[9] S. A. O. Silva, P. F. Donoso-Garcia, P. C. Cortizo and P. F. Seixas, "A Three-Phase Line-Interactive UPS System Implementation with Series-Parallel Active Power-Line Conditioning Capabilities," IEEE Trans. on Industry Applications, vol. 38, no. 6, pp. 1581-1590, 2002.

[10] A. Nasiri, A. E. Amac and A. Emadi, "Series-Parallel Active Filter/Uninterruptible Power Supply System," Electric Power Components and Systems Journal, vol. 32, no.11, pp. 1151-1163, 2004.

[11] S. J. Jeon and G. H. Cho, "A Series-Parallel Compensated Uninterruptible Power Supply with Sinusoidal Input Current and Sinusoidal Output Voltage," in Proc. of IEEE PESC, pp. 297-303, 1997.

[12] B-H. Kwon, J-H. Choi and T-W. Kim, "Improved SinglePhase Line Interactive UPS," IEEE Trans. on Industrial Electronics, vol. 48, no. 4, pp. 804-811, August 2001. 